E.L.U.A. 2, 1984, págs. 201-206

\title{
¿QUIÉN ES NOSOTROS?
}

\author{
JOSÉ LUIS RIVAROLA \\ (Pontificia Universidad Católica del Perú. Lima)
}

Uno de los textos del poeta alemán Helmut Heissenbüttel, titulado "Reducción gramatical», plantea con austera dialéctica un problema cuya complejidad es objeto de estas páginas y cuya formulación más simple y concisa se puede presentar en la forma de la pregunta que sirve de encabezamiento. En efecto, el primer párrafo de dicho texto reza como sigue:

Si yo no sólo fuera yo sino nosotros sería yo tú, él ella. Como yo soy yo y no nosotros yo soy yo y sólo puedo hablar de mi. Si yo fuera nosotros yo hablaría de nosotros cuando yo hablo de mí. Como yo soy yo y sólo puedo hablar de mí no hablo de nosotros. Pero pienso hablando de mí [como si nosotros]. Hablo corno si yo fuera nosotros. [Nosotros seriamos nosotros si pudiéramos hablar de nosotros. Nosotros no tiene habla. Nosotros es un fantasma hecho de yo más yo más yo. Este fantasma yo más yo más yo es un fantasma porque nosotros no podemos hablar de nosotros] '.

1 Helmut Heissen büttel, Das Textbuch, Berlín (1970, p. 55). La traducción es mia. He aquí el texto original: "Wenn ich nicht nur ich wäre sondern wir wäre ich du er sie es. Da ich ich bin und nicht wir bin ich ich und kann nur von mir reden. Wenn ich wir wäre würde ich wenn ich von mir rede von uns reden. Da ich ich bin und nur von mir reden kann rede ich nicht von uns. Aber ich denke indem ich von mir rede [als ob wir]. Ich rede als ob ich wir 
Es decir, la condición de la existencia es la capacidad de hablar: yo existe porque habla, nosotros no existe porque no habla. Pero entonces ¿qué nombra nosotros? ${ }^{2}$, ¿qué clase de fantasma es éste que aparenta hablar?, ¿quién habla cuando nosotros aparenta que habla?, ¿cuál es el parentesco entre nosotros y yo?, ¿qué forma de existencia es atribuible a nosotros? No todas estas preguntas son de orden estrictamente lingüistico, no obstante lo cual subyace a todas ellas la cuestión de la naturaleza de la oposición entre las formas pronominales yo y nosotros. A partir de la existencia misma de la oposición lingüística se instaura una problemática referencial con diversos alcances, fundamentalmente ontológicos y psico-sociales.

Yo y nosotros, al igual que tú, vosotros, etc., son exponentes pronominales de las «personas gramaticales». Estas constituyen entidades lingüisticas de naturaleza deíctica, es decir, unidades cuyo significado contiene por lo menos un elemento que identifica la función de ellas en relación con el acto comunicativo. En la deixis personal, de que aqui se trata, las «personas» corresponden, por una parte, a las instancias de una oposición entre "punto cero del habla" (es decir, origen del sistema deíctico de coordenadas) y punto no cero (es decir, todo lo que no constituye origen del sistema) ${ }^{3}$. La "primera persona" se identifica con dicho punto cero: yo designa a quien habla en el acto comunicativo. Las otras "personas" corresponden al punto no cero deíctico, es decir, a quienes no hablan. Pero, por otra parte, quienes no hablan pueden participar o no en el acto comunicativo: la "segunda persona" corresponde a quien, sin hablar, participa: tú designa, así, a una instancia que participa en el acto comunicativo en la medida en que quien habla la instaura como receptor. En este sentido estricto de participación, es decir, en el sentido de la dualidad constitutiva de todo acto comunicativo, es que la "primera" y la "segunda persona" son participantes. En cambio, la llamada "tercera persona" queda definida nega-

wäre. WWir wăren wir wenn wir von uns reden könnten. Wir hat keine Rede. Wir ist ein Phantom aus ich plus ich plus ich. Dieses Phantom ich plus ich plus ich ist ein Phantom weil wir nicht von uns reden können.]". En la traducción no he mantenido siempre los pronombres obligatorios del alemán. Por lo demás, he suprimido el neutro.

2 Con la palabra en letra cursiva me refiero a la forma pronominal; con la equivalente en letra redonda aludo al cuestionado denotatum.

3 Sobre la deixis personal, cf. K. Heger, «Deixis personal y persona gramatical», en Teoría semántica, II, Madrid (1974, pp. 33-51). Véase también E. Benveniste, «Estructura de las relaciones de persona en el verbo", "La naturaleza de los pronombres", "De la subjetividad en el lenguaje", incluidos en Problemas de lingaistica general, México, 1971. El primero de los trabajos mencionados de Benveniste trata en particular del valor de nosotros. 
tivamente por partida doble: él o ella designan a los que no hablan y no participan, de donde se explica que a esta "tercera persona" se la haya podido considerar como la no-persona ${ }^{4}$. Con el fin de facilitar ulteriores reflexiones se utilizarán los siguientes términos y siglas: $1{ }^{a}$ persona $=\mathrm{OE} ; 2 .^{\mathrm{a}}$ persona $=\mathrm{OE} ; 3 \mathrm{.}^{\mathrm{a}}$ persona $=\mathrm{OE} \mathrm{s}$.

Asi pues, quien dice yo se autodesigna como el que hace uso en ese hic et nunc de la posibilidad de hablar: yo nombra al punto del que emana el discurso, lo que E. Benveniste ha llamado el "sujeto de la enunciación», esto es, el sujeto (el individuo) que enuncia ${ }^{6}$. El sujeto de la enunciación puede, ciertamente, autodesignarse pero cuando se autodesigna por medio de yo este yo es necesariamente también el "sujeto del enunciado», esto es, una función sintáctica dentro de la estructura verbal del discurso ${ }^{7}$. ¿Y nosotros?

Nosotros comparte con yo la naturaleza deíctica: también nosotros es punto cero del habla, primera persona. A diferencia de yo, sin embargo, es una primera persona 'plural'. Pero ¿qué quiere decir 'plural' en este caso? La especial naturaleza deíctica implicada no permite contentarse con la simple extrapolación de lo que significa el plural frente al singular en otros casos, a saber, sea una cuantificación definida o indefinida de los individuos que constituyen la clase, cuando se trata de palabras correspondientes a conceptos generales discontinuos (el gato: cuatro gatos: algunos gatos), sea una cuantificación de subclases incluidas en la clase constituida por el singular, cuando se trata de palabras correspondientes a conceptos generales continuos (la ha-

4 Cf. al respecto E. Benveniste, «Estructura de las relaciones...» (cit.). Benveniste contrapone (1) una correlación de personalidad que opone yoltú a la no-persona él; y (2) una correlación de subjetividad que opone, dentro de la anterior, yo a tú. E. Coseriu, Lecciones de lingüistica general, Madrid, 1981, p. 27, menciona un antecedente de estas ideas en Hermes, de J. Harris, Londres, 1751.

5 Las siglas provienen de K. Heger, "Deixis personal..." (cit.); O. vale por "punto cero" y E por "(Sprech-) Ereignis» = acto de habla.

6 E. Benveniste, «El aparato formal de la enunciación", incluido en Problemas de lingüistica general, II, México, 1977. El uso que hace Benveniste de sujeto no es el mismo en el caso de "sujeto de enunciación" que en el de "sujeto del enunciado" (cf. más adelante en el texto). En el primero, "sujeto" es una categoria pragmática, en el segundo una categoría sintáctica.

Naturalmente yo puede aparecer en discursos citados por otro sujeto de enunciación; pero en este caso también designa al sujeto de la enunciación secundaria, incrustada en la enunciación primaria. En la ficción, yo puede designar asimismo a un sujeto de enunciación no coincidente con el sujeto de la enunciación no autodesignado, del que emana el discurso que el sujeto de enunciación autodesignado postula como suyo. 
rina: las harinas). ¿Constituye nosotros una suma de yo más yo, etc.? ¿Es imaginable una cuantificación de quien habla?, ¿es un sujeto de enunciación plural el que se autodesigna con nosotros?, ¿son varios yo los que hablan cuando nosotros ocupa el lugar de sujeto de enunciado?".

En este punto es necesario separar con cuidado, por una parte, las posibilidades teóricas relativas a una pluralización de la primera persona (OE), es decir, a una multiplicación del elemento deictico por un elemento cuantitativo $>1^{4} \mathrm{y}$, por otra parte, el significado de nosotros en castellano.

En lo que respecta a lo primero las posibilidades son tan infinitas como infinitos los posibles multiplicadores:

$\mathrm{OE} \cdot 2=2 \mathrm{OE}$
$\mathrm{OE} \cdot 3=3 \mathrm{OE}$
$\mathrm{OE} \cdot 4=4 \mathrm{OE}$
etc.

En cualquiera de estos casos se tendría sujetos de enunciación simultáneos. Esta infinitud sólo está limitada por las posibilidades pragmáticamente viables y relevantes. En la praxis comunicativa propia de la cultura occidental esta simultaneidad se da sólo excepcionalmente en el plano oral y algo más frecuentemente en el escrito ${ }^{10}$. Pero es fácil-

* Para O. Jespersen (The philosophy of grammar, Londres, 1924, p. 192), p. e., la primera persona no puede existir propiamente sino en singular, Opinión similar se encuentra en J. Lyons, Introduction to theoretical linguistics, Londres, 1968, p. 277.

- Sobre las posibilidades teóricas de la combinación de la deixis personal con el número y sobre los sistemas de numerosas lenguas a este respecto, cf. K. Heger, Sprachvergleich und Semantik. Das Beispiel der grammatischen Kategorien 'Person' und 'Numerus' (Sitzungsberichte der Heidelberger Akademie der Wissenschaften. Philosophisch-historische Klasse), Heidelberg, 1980.

10 Dejo de lado, en esta ocasión, la asimetria entre ambos planos, y no entro a discutir los problemas relativos a las diferencias entre la producción del discurso y su materialización final (o sus materializaciones intermedias) en el caso de la lengua escrita. Benveniste (“Estructura...”, cit., 168) parece excluir la posibilidad de que nosotros designe varios sujetos de enunciación simultáneos cuando señala: "Si no puede haber varios 'yo' concebidos por el 'yo' mismo que habla, es que 'nosotros' es, no ya una multiplicación de objetos idénticos, sino una yunción entre 'yo' y 'no-yo'". Es claro que, en el contexto de la presente reflexión, no se trata de esto, sino de sujetos de enunciación simultáneos, independientemente de cómo conciba cada uno de ellos a los otros. 
mente imaginable que alguna lengua pudiera recoger en las formas de su sistema deíctico p. e. las dos posibilidades siguientes:

$\mathrm{OE} \cdot 2=2 \mathrm{OE}$

$\mathrm{OE} .>2=\mathrm{nOE}$

Tal lengua dispondría - fuera de una designación para OE . 1- de una forma dual para designar el caso de dos sujetos de enunciación simultáneos y una forma plural para designar el caso de más de dos.

En lo que atañe a lo segundo, el castellano no hace la distinción: si bien, obviamente, nosotros puede ser utilizado para referir a situaciones de dos $O E$ y de $n O E$, la diferencia no forma parte de su significado. Ahora bien: como es obvio, nosotros - y formas equivalentes, en numerosas lenguas - implica una cuantificación que puede involucrar también a la segunda y a la tercera persona. Al respecto, es necesario considerar -independientemente de nosotros- las posibilidades teóricas correspondientes, las cuales son igualmente infinitas que en el caso anterior y por las mismas razones. Se mencionarán algunas a continuación:
a) $\mathrm{OE}+\mathrm{OE}$
b) $\mathrm{OE}+\tilde{O E}$
c) $O E+O E \cdot 2 \dot{O} \cdot>2$
d) $\mathrm{OE}+\mathrm{OE} \cdot 2 \dot{O} \cdot>2$
e) $\mathrm{OE} \cdot 2$ ó. $>2+\mathrm{OE}$
f) $\mathrm{OE} \cdot 2$ ó.>2+OE. 2 ó.$>2$
g) $\mathrm{OE} \cdot 2$ ó.>2+ $\mathrm{OE} \cdot 2$ ó.$>2$
h) $\mathrm{OE}+\mathrm{OE} \cdot 2 \mathrm{O} \cdot>2+\overline{\mathrm{OE}} \cdot 2 \mathrm{O} \cdot>2$
i) $\mathrm{OE} \cdot 2 \dot{o} \cdot>2+\mathrm{OE} \cdot 2$ ó $\cdot>2+\mathrm{OE} \cdot 2 \dot{o} \cdot>2$

De c) a i) se encuentran combinaciones que corresponden a la distinción que realizan muchas lenguas (entre ellas el quechua, p. e.) entre el llamado 'plural inclusivo' (que incluye a $\mathrm{OE}$ ) y el 'plural exclusivo' (que excluye a $\mathrm{OE}$ ). Las posibilidades a) y b) corresponderian a formas de dual que no será tan fácil documentar en lenguas existentes. Pues, en verdad, la mayoria de los idiomas realizan en su sistema deictico personal pocas de estas distinciones: grosso modo, puede trazarse una gran división entre los que pluralizan en combinación con las categorias 'inclusivo' y 'exclusivo' y los que no lo hacen. El castellano y la mayoría de los idiomas indoeuropeos está entre estos últimos.

Nosotros (y sus variantes desinenciales o de caso), por consiguiente, no es sensible a ninguna de las distinciones que se han seña- 
lado. Este plural sólo significa "presencia de varios individuos" y nada tiene que ver con el número de emisores ". Los "varios individuos" pueden ser dos o más $\mathrm{OE}$, o diversas combinaciones de $\mathrm{OE}$, $\mathrm{O} E$ y $\bar{O} \bar{E}$; pero éstas no son realizaciones en el habla del significado de nosotros - 'variantes' de su núcleo semántico, sino solamente lo referido en cada caso particular, es decir, la realidad extralingüística que en cada ocasión se denota ${ }^{12}$. Ahora bien, lo referido suele ser en la praxis comunicativa no dos o más sujetos de enunciación simultáneos (cf. nota 9), sino un solo sujeto de enunciación en co-presencia de otro(s) individuo(s) que el sujeto de enunciación integra a su discurso, que hace hablar a través de su voz. Esta co-presencia no es obligadamente, por cierto, una co-presencia física; puede ser una co-presencia diseminada en el espacio o diferida en el tiempo; puede ser, finalmente, una co-presencia de carácter representativo, cuando el sujeto de enunciación considera que su habla expresa una intención colectiva o que su persona, por fuerza de su investidura, es símbolo de una pluralidad que queda reflejada en la autodesignación plural. Este último caso que corresponde al plural llamado mayestático es el más extremo testimonio de la unicidad que subyace a la mayoría de los usos de nosotros, como que el habla es radicalmente individual. Nosotros no tiene habla. Nosotros es un yo camuflado, un fantasma hecho de yo, tú, él, ella, fantasma con el que muchas veces se pretende sea aumentar la valencia del propio discurso en la postulación de un hablante plural o colectivo, sea refugiarse en esa fementida pluralidad para evitar el relieve de la propia persona o para diluir la responsabilidad irrenunciable sobre el propio hablar ${ }^{13}$. Nosotros, pues, es un plural bien singular.

"Cf. al respecto L. J. Prieto, “Una nota de gramática: 'nosotros' ¿plural de 'yo'?», en Estudios ofrecidos a Emilio Alarcos Llorach, Tomo I, Oviedo, 1977, pp. 209-216. Benveniste, en cambio ("Estructura..., cit., 170) niega que haya cuantificación en nosotros: “No es un 'yo' cuantificado o multiplicado, es un 'yo' dilatado más allá de la persona estricta, a la vez acrecentado y de contornos vagos".

12 En este punto yerra, en nuestra opinión, L. J. Prieto, art. cit., al considerar como variantes de significado lo que no es sino la variedad de denotata.

1.) Cf: "Cuando una persona habla de si misma como 'nosotros' en vez de 'yo' puede deberse en muchos casos a una modesta renuencia a imponer su propia persona a sus oyentes o lectores; esconde su propia opinión o acción detrás de las de otros. Pero esta práctica puede deberse incluso más frecuentemente a un sentido de superioridad, como en el 'plural mayestático'» (O. Jespersen, op. cit., p. 13; mía la traducción). 